\title{
Reflections on September 11: Lessons From Four Psychological Perspectives
}

\author{
Kevin Lanning* \\ Honors College, Florida Atlantic University
}

Several of the major theoretical perspectives within psychology can contribute to our understanding of the September 11 attacks and their aftermath. An argument derived from the psychodynamic approach suggests that terrorism may be a product of ambivalence rather than anger. From an evolutionary standpoint, the resentment that breeds terrorism, and the altruism that has arisen in its wake, may be seen as two sides of the same coin. The decision theoretic approach suggests that in the attempt to prevent future terrorist attacks, we face a seeming tradeoff between civil rights and civil liberties. Finally, the personality development approach suggests that difficult times can help forge new moral leaders.

Traditional personality theories have been ambitious in scope, simultaneously aspiring to understand individual differences, cultural comparisons, and universals of human nature-the ways in which we are "like all other men, like some other men, and like no other man" (Kluckhohn, Murray, \& Schneider, 1953). These three levels of analysis are a convenient framework to begin considering the role of psychology in the tragic events of September 11.

At the level of the individual, we might strive to understand the personality of Mohammed Atta, alleged to have piloted the first plane to slam into the World Trade Center, or that of New York City Mayor Rudy Giuliani, whose leadership in the wake of the crisis was widely hailed. But while biography is compelling, it is easy to overestimate the role of the individual in shaping history (Boring, 1950), just as it is easy to neglect situational factors in understanding behavior (Ross, Amabile, \& Steinmetz, 1977).

*Send correspondence to Kevin Lanning, Honors College of Florida Atlantic University, 5353 Parkside Drive, Jupiter, FL 33458. [e-mail: lanning@fau.edu]. The author would like to thank Tim Steigenga and Julie Earles for the comments on an earlier draft of this essay. 
Similarly, at the level of culture, we might strive to understand the strain of Islamic fundamentalism of the al-Qaida group, as well as the preoccupations that were the stuff of American lives prior to the tragedy. There is no doubt that many of us in the West have little understanding of the many variants of Islam. But while the psychological study of culture can illuminate, it risks, particularly in the current mood, a reification of seeming differences, and can too readily lead to a depersonalization of the other.

It is the third level of analysis that seems most compelling in the wake of September 11. The traditional personality theories of the last century were, in large part, a response to world wars and economic struggles. ${ }^{1}$ In the face of today's challenges, it seems appropriate to again consider the nature of human nature. In the following paragraphs, I introduce a few ways in which four psychological theories or perspectives can shed light on the attacks and their aftermath.

\section{From Psychodynamics: The Importance of Ambivalence and Anxiety}

What are the roots of the hatred against America? Though Osama bin Laden has not accepted responsibility for the events of September 11, he remains the prime suspect as the instigator of the attack, and several years prior to the attack, he issued a declaration of war against America. The rationale behind his fatwa was ostensibly the continued U.S. military presence in Saudi Arabia, which has been characterized as an occupation of holy land by infidels. But the phenomenon to be understood is not the fatwa itself, but the willingness of his followers to adhere to it.

The key lesson of the psychodynamic perspective is that we may not be aware of the motives governing our behavior, a lesson that has been reinforced by innumerable studies in experimental psychology (e.g., Erdelyi, 1985; Nisbett \& Wilson, 1977). So while the fatwa and, behind it, the presence of American troops on sacred soil may be the conscious motive in the minds of the followers of Osama bin Laden, other motives may also be salient in energizing anti-American sentiment. ${ }^{2}$ Even the strongest critic of American foreign policy must acknowledge that there is no necessary causal link between the actions of our government and the willingness of terrorists to give their own lives while taking the lives of others. There must be deeper motives at play.

The present conflict can be usefully understood as a conflict within individual minds as well as a conflict between cultures. The psychodynamic approach and

${ }^{1}$ For example, Freud's (1920/1975) death instinct was a response to the carnage of the Great War. Allport's (1937) radical individualism can be seen as the antithesis of the deindividuating fascism then ascendant in Germany and elsewhere. Fromm (1941) suggested that human distress was attributable, in part, to imperfections in society.

2 It should be noted that Prince Sultan Air Base, which houses the majority of American, British, and French air troops in Saudi Arabia, is at least 500 miles away from the holy sites of Mecca and Medina. 
Islam are largely in agreement here. Mohammed spoke of a greater and lesser jihad; the greater is the struggle against one's own temptation, the lesser is the protection of Islam against perceived enemies. The greater jihad is infinitely more difficult, so our attackers turn away from it; rather than acknowledge the strength of their own temptation, they struggle instead against what they see as a land of unveiled women and unabashed greed. The ostensive moralism and righteousness of the terrorists appears, like much moralism and righteousness, to be a reaction formation against an inner battle. ${ }^{3}$

The psychodynamic approach can potentially shed light on the victims as well as the instigators of terrorism. Terror management theory (Pyszczynski, Greenberg, \& Solomon, 1997) suggests that a primary human motive is to reduce the anxiety that accompanies awareness of our mortality. An exposure to death and an increase in the salience of mortality weakens the cultural anxiety buffer and leads to a range of actions to protect self-esteem. These include "more favorable evaluations of those who exemplify cultural values ... behavioral avoidance of outgroup members ... increased conformity to cultural standards ... and increased difficulties and emotional distress when behaving counter to cultural norms ..." (Pyszczynski et al., 1997, p. 3). These effects anticipated by terror management theory appear to parallel those observed in American attitudes in the weeks since September 11.

When the psychodynamic approach moves from conjectures about human nature to distal attempts to portray unique individuals, it is on shakier ground. During World War II, official reports by the OSS ascribed a number of pathologies to Hitler that were later found not to exist (Hastie \& Dawes, 2001). Today, the limited work on terrorism and personality suggests that "most terrorists do not demonstrate serious psychopathology" (Post, 1990, p. 31). Certainly the functionaries of terror, whose deadly contributions consisted of the analysis of airline schedules or the clinical refinement of anthrax, are probably disturbingly unremarkable (Arendt, 1963). It seems that if the psychodynamic approach is to help us understand the psychology of terror, it will do so not by showing how terrorists are different from us, but how they are the same.

\footnotetext{
${ }^{3}$ According to a number of news reports, several men who knew of the impending attacks are alleged to have spent hundreds of dollars on drinks and lap dances at a Florida strip club just prior to the attacks, all the while ranting about the evils of America (Miniter, 2001). Further, the unusual amount of short selling of airline stocks on September 10 suggests that individuals with knowledge of the attacks were, at the very least, comfortable in the ways of the Wall Street they sought to destroy (Radlauer, 2001). These allegations, if true, are consistent with the argument that ambivalence, not anger, was at the root of the attacks.
} 


\section{From Evolutionary Psychology: Envy and Altruism}

The September 11 attack was an attack against the world's only superpower, whose cultural might extends to or threatens every corner of the globe. For much of the Third World, the lesson of September 11 is that there must be "... more global reflection on the multiple inequalities and injustices that feed impotence and desperation ... the battle that must be waged is the battle against the silent bomb of hunger, poverty, and social exclusion, a bomb that is produced by the structural injustice, both economic and political, that is suffered by the majority of the world's peoples" (Menchú Tum et al, 2001).

One implication of this analysis is that America is vulnerable to attack because of its relative wealth. Yet why should relative wealth lead to terrorism? One answer draws on evolutionary psychology: A predisposition to resentment may have been effectively selected during our ancestral history. If we faced profound scarcity during significant and lasting portions of our history, then there may have been survival advantage to parents who channeled their limited resources to a single child, while letting other children wither or fend for themselves (Scheper-Hughes, 1985). If early humans faced Sophie's Choice not once, but repeatedly, over many generations, the children who survived would have been not merely the strongest, but also the most vigilant against potential sibling advantage. The children who survived are our ancestors, and those of our attackers, and we are all equipped with a sensitivity to unequal treatment. If it is human nature to be sensitive to the distribution of resources, then perhaps the seeds of terrorism lie in the resentment bred from inequality.

The argument that inequality breeds resentment does not require evolutionary metatheory. For example, Lewin, in his Principles of Topological Psychology (1936), recognized that inequalities lead to unstable boundaries, and Feather (1999) has described the human tendency to resent "tall poppies" (high achievers), particularly when these individuals are seen as undeserving of their high status. When considered in this light, an evolutionary explanation of resentment may appear to be superfluous. The real strength of the evolutionary approach may lie in its ability to illuminate an additional part of the story of September 11, and that is the altruism we observed in the wake of the tragedy.

A number of evolutionary explanations of altruism have been advanced (Krebs, 1998). If we are equipped to be vigilant against unequal treatment, it seems that we should be similarly equipped to perceive and respond to the needs of others. Where resources are not scarce, it is in our genetic interest for our siblings to survive and prosper. If our ancestors faced competition, they also faced innumerable problems whose successful resolution demanded thoughtfulness and cooperation. ${ }^{4}$

\footnotetext{
${ }^{4}$ An evolutionary basis for altruism, if it exists, would not imply that heroism is reducible to mere reflex. The firefighter who climbed the stairs of the World Trade Center as hundreds descended, seeking
} 
The human proclivity to be simultaneously vigilant against unfairness yet ready to cooperate are two sides of the same coin, as both are products of a social history shaped by the need for reciprocity (Tooby \& Cosmides, 1992). This same need for reciprocity has been voiced repeatedly by the leaders of America and its allies in the weeks since the tragedy. In the language of iterative prisoner's dilemma games, reciprocity is a sound strategy, as a failure to reciprocate allows further victimization. But from another perspective, retribution for the sake of retribution alone is ultimately irrational, as it is an attempt to recapture a sunk cost (Hastie \& Dawes, 2001). We cannot recapture the lives that have been lost; we must focus only on the prevention of future deaths.

\section{From Decision Theory: The Tension between Civil Rights and Civil Liberties}

The game-theoretic or economic analysis of the last paragraph can be extended to a consideration of the costs and benefits of different cultural responses to the challenge before us. In a five-week period after the initial attacks, there were more than 170 reports of hate crimes against individuals perceived to be Arabs and Muslims within the United States. This statistic is surely only the tip of the iceberg: For every hate crime that has been reported, there have been a hundred slights, and more than slights, levied against women, men, and children because of their foreign appearance, their foreign names, or their religious beliefs. The story is not a new one, but it remains important, for these individuals are also casualties of the war against terrorism. Decision theory, in particular Signal Detection Theory (SDT; Swets, Tanner \& Birdsall, 1961) can be used to shed some light on the civil liberties and civil rights issues at hand.

In SDT, the problem is to detect a signal of varying strength against a background of noise, whose strength may also vary. The two distributions (signal + noise and noise alone) are overlapping. Above a given threshold, a stimulus is identified, rightly or wrongly, as a "signal." Below this threshold, the stimulus is treated as noise. This can be represented schematically, as in Figure 1.

A decision threshold ( $B$, represented by the vertical line) divides each of the two curves. Moving from left to right across the diagram, the threshold divides the "noise" curve into areas of Correct Rejection and False Positive. Similarly, the threshold divides the rightmost "signal + noise" curve into areas of Miss and Hit.

As the curves become distant, the proportion of the curves in the areas of False Positive and Miss become reduced. If the curves are not overlapping, one could perfectly distinguish the two distributions. Conversely, as the curves approach

in vain to save other lives, did not act because of a biological imperative. Behavior is not inherited, but predispositions may be, and the predisposition to help, though too rarely acted upon, is nonetheless part of human nature. 


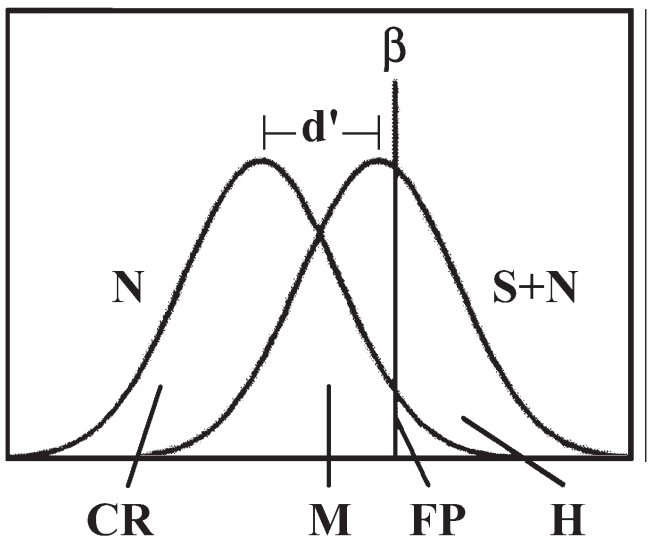

Figure 1. Basic concepts in Signal Detection Theory. N: Noise, S+N: Signal + Noise, d': Sensitivity, $\beta$ : Threshold, CR: Correct Rejection, M: Miss, FP: False Positive, H: Hit.

each other, the number of errors increases. The distance between the two curves, symbolized as $\mathrm{d}^{\prime}$, can be understood as the amount of information available for distinguishing the two groups.

For any given d', there is a direct tradeoff between the two types of errors. As the decision threshold $(\beta)$ moves to the left, the proportion of Misses will decline, but the proportion of False Positives will increase. Similarly, as the threshold moves to the right, a reduction in False Positives obtains, but only at the cost of an increase in Misses. The optimal threshold will be a function of both the perceived relative frequency of the two distributions and the relative costs of the two types of errors. If the signal is common, or if the cost of a Miss is perceived to be particularly great, the decision threshold should move in a more conservative direction.

Moving to the present problem, the two distributions represent "nonterrorists" (noise) and "terrorists" (signal + noise). A Miss represents the failure to recognize a terrorist and the potential for cataclysm. A False Positive represents the misidentification of a nonterrorist, the mistaken detainment of an individual. But because terrorists are, presumably, rare, the number of nonterrorists dwarfs that of terrorists, and any decision threshold will lead to more False Positives than Hits. For every terrorist correctly identified, many innocent individuals will be detained and suffer the slights of social mistrust. Because the cost of a Miss is now prohibitively high, many in our culture appear willing to pay this price-particularly since the cost will be disproportionately borne by others.

It is crucial for psychologists to remind the broader culture of the cost of False Positives - the cost of mistrust and social stigma and all that they engender. But we should keep in mind the cost of Misses as well, and ask ourselves if an elevated 
decision threshold is in the social interest. The tradeoff between Misses and False Positives occurs only for a particular level of information; with more information, fewer False Positives will be detected for a given proportion of Hits. But information itself has a cost: Americans value their privacy, and may be unwilling to surrender the types of information — such as records of credit card purchases, library books borrowed, and Internet sites visited — which could conceivably increase the ability of security personnel to identify terrorists. In the absence of such information, security personnel will continue to work from the weak and debilitating cues of surname and apparent race, and Islamic Americans will bear a disproportionate price for the terrorism we fear. A Signal Detection analysis suggests that, if our society is to respond at all to the risk of terrorism, we face a tradeoff between civil liberties, such as the right to privacy, and civil rights, such as freedom from racial profiling and other forms of prejudgment from superficial cues.

\section{From Studies of the Self and Development: Trauma Can Spur Maturation}

The self-concept is defined in part by the groups to which we belong (Tajfel, 1982). Terrorism is not about conflicting world views, but conflicting self-views. Among the men who instigated this terror, there is the belief that America seeks the destruction of their androcentric culture, their religion and, in a sense, their identities. Among the women, men, and children who are victims of terror, there is now a reexamination of who we are and, in many of us, a reaffirmation or reexamination of that part of the self that is identified with country.

Psychology is more than the study of psychopathology, and while we may suffer more from depression, anxiety, and stress-related disorders now than we did before September 11, other personality changes may be equally profound and consequential. Dramatic events leave our quotidian scripts ineffective; they strip away our overlearned and automatic responses, and lead us to a reexamination of our priorities.

There is some evidence that environmental trauma can magnify preexisting differences in personality (Caspi \& Moffitt, 1993), possibly including preexisting differences in moral or ego development (Hy \& Loevinger, 1996). If trauma can accelerate or retard maturation, then the horror that we have begun to witness should cause some to regress to self-protection while others progress towards greater thoughtfulness and compassion (Lanning, Edwards, Colucci, Holm, Kane \& Rosenberg, 2001). The great nonviolent leaders of the 20th century, Gandhi and King, were galvanized by the struggles they faced. We can only hope that tomorrow, new leaders will be forged to help lead the peace effort, and that they will help us to understand and overcome human weakness through insight and understanding. 


\section{References}

Allport, G. W. (1937). Personality: A psychological interpretation. NY: Holt.

Arendt, H. (1963). Eichmann in Jerusalem: A report on the banality of evil. NY: Viking.

Boring, E. G. (1950). Great men and scientific progress. Proceedings of the American Philosophical Society, 94, 339-351.

Caspi, A., \& Moffitt, T. E. (1993). When do individual differences matter? A paradoxical theory of personality coherence. Psychological Inquiry, 4, 247-271.

Erdelyi, M. H. (1985). Psychoanalysis: Freud's cognitive psychology. New York: Freeman.

Feather, N. T. (1999). Judgments of deservingness: Studies in the psychology of justice and achievement. Personality \& Social Psychology Review, 3, 86-107.

Freud, S. (1920/1975). Beyond the pleasure principle. New York: Norton.

Fromm, E. (1941). Escape from freedom. New York: Holt, Rinehart, \& Winston.

Hastie, R., \& Dawes, R. M. (2001). Rational Choice in an Uncertain World. Thousand Oaks, CA: Sage.

Hy, L. X., \& Loevinger, J. (1996). Measuring ego development (Second Edition). Mahwah, NJ: Erlbaum.

Kluckhohn, C., Murray, H. A., \& Schneider, D. M. (1953). Personality in nature, society, and culture (2nd ed.). New York: Knopf.

Krebs, D. L. (1998). The evolution of moral behaviors. In C. B. Crawford et al. (Eds.) Handbook of evolutionary psychology: Ideas, issues, and applications. Mahwah, NJ: Erlbaum, p. 337-368.

Lanning, K. Edwards, J., Colucci, J., Holm, J. Kane, S., \& Rosenberg, A. (2001). Effects of terrorism on responses to Loevinger's Sentence Completion test. Study in progress.

Lewin, K. (1936). Principles of topological psychology. New York: McGraw-Hill

Menchú Tum, R., Maguire, M. C., \& Esquivel, A. P. (2001). Letter to UN Secretary General Kofi Annan. http://www.thecommunity.com/crisis/letter_annan.pdf

Miniter, R. (2001). The Iraqi Connection. Wall Street Journal, September 24, 2001. http://www. opinionjournal.com/columnists/rminiter

Nisbett, R. E., \& Wilson, T. D. (1977). Telling more than we can know: Verbal reports on mental processes. Psychological Review, 84, 231-259.

Post, J. M. (1990). Terrorist psycho-logic: Terrorist behavior as a product of psychological forces. In W. Reich (Ed.) Origins of terrorism: Psychologies, ideologies, theologies, states of mind. Cambridge: Cambridge University Press, pp. 25-42.

Pyszczynski, T., Greenberg, J., \& Solomon, S. (1997). Why do we need what we need? A terror management perspective on the roots of human social motivation. Psychological Inquiry, 8, 1-20.

Radlauer, D. (2001). Black Tuesday: The world's largest insider trading scam? Report of the International Policy Institute for Counter-Terrorism; http://www.ict.org.il/articles/articledet.cfm? articleid $=386$

Ross, L. D., Amabile, T. M., \& Steinmetz, J. L. (1977). Social roles, social control, and biases in social-perception processes. Journal of Personality \& Social Psychology, 35, 485-494.

Scheper-Hughes, N. (1985). Culture, scarcity, and maternal thinking: Maternal detachment and infant survival in a Brazilian shantytown. Ethos, 13, 291-317.

Swets, J. A., Tanner, W. P., \& Birdsall, T. G. (1961). Decision processes in perception. Psychological Review, 68, 301-340.

Tajfel, H. (1982). Social psychology of intergroup relations. Annual Review of Psychology, 33, 1-39.

Tooby, J., \& Cosmides, L. (1992). The psychological foundations of culture. In Barkow, Jerome H., \& Cosmides, Leda, Ed; et al. The adapted mind: Evolutionary psychology and the generation of culture. Oxford: Oxford University Press, New York.

KEVIN LANNING (lanning@ fau.edu.) is book review editor of ASAP and founder of http://Florida2002.org., a grassroots political action group aimed at electorial reform. His primary interests are in personality measurement and development. 